\title{
Study on an Architect-Oriented approach of Structural Performance-based Design
}

\author{
> YONGHENG HU \\ University of Applied Arts Vienna, Austria \\ toto4356@gmail.com
}

\author{
DINYING LI \\ University of Michigan, USA \\ liqinying@gmail.com
}

\begin{abstract}
For most architects, it is not easy to transform their free form of designs into constructable building without precise knowledge structural design and more often the architect need ask structural engineer for consultation. Yet the structural performance of building itself provides possibility for the architect to explore a new form-finding procedure and An approach is introduced in this article and it could be adopted by architects concerning the works of predicting the structural performance in the early design stage. The approach has been developed throughout the architecture history and recently it turns into a computational methodology for architectural design. This article analysis the structural performance design history in architect's view, compares and explain the current Structural performance-based design methodology and evaluate its value for architecture design.
\end{abstract}

Keywords: Performance-Based Design, Structural Optimization, Form-Finding, Computational Design, Tectonic Innovation.

\section{Introduction}

Architectural design method based on the structural performance of architects through the structure properties (structural stability, material characteristics, span relations, seismic performance, etc.) characteristics were analyzed in the architectural design process to find the spatial form and structure through simulation, calculation and optimization process reasonable relationship between the design process.

Including the design of building structures in the early Renaissance architect's responsibilities in. Produced a church dome, colonnades and other structures of space and time in religious buildings and other public building design. The spatial structure in order to create a connection, not only to meet the applicable economic, aesthetic premise, but also demonstrating the potential relevance of the building and its structural characteristics of the prototype space. In the limited technical and economic basis, an important component of the architect through the basic concepts of reasonable structure design to minimize unnecessary use of materials and to maximize the characteristics of the structure of the building itself, the historical development of architectural culture has become section.

\section{Background}

The late Renaissance, due to construction work systematic, mature and complex, had mastered the entire process of building and structural design architects gradually lost control and construction process for the structural design of the master. Until then, the division of the Industrial Revolution makes the boundaries between architects and engineers become more clear: to achieve technical operations engineers pay more attention to the spatial structure, the architects are more concerned about the relationship between architecture and the process of achieving social function; engineers need to undertake operations related to the safety of building the physical characteristics of the contents of personnel, organizational design and construction process material testing, architects must consider the impact of the spread of culture and the concept of architecture.

This differentiation makes the structural performance of traditional design process into a passive design, the architect becomes a structural engineer to meet the regulatory requirements of both the subordinate items. Architects need to cooperate to achieve the creation and assessment of the audit by the structural engineer, which makes architectural design of the production process into a process to achieve both performance requirements. With the rapid development of computer technology, many continue to develop simulation calculation software content, structure and material properties and other properties can be simulated, analyzed and optimized. Although various target structure for performance analysis tools continue to improve, but the process is still entirely in the hands of the structural engineer. Structural performance analysis, as a new design approach can become a means of architects looking shape. Architects and structural engineers how to break the boundaries of design and enables us to establish a new collaborative relationships, and promote the integration architecture and interaction design to create the perfect combination of space and structure between the quality of construction. 


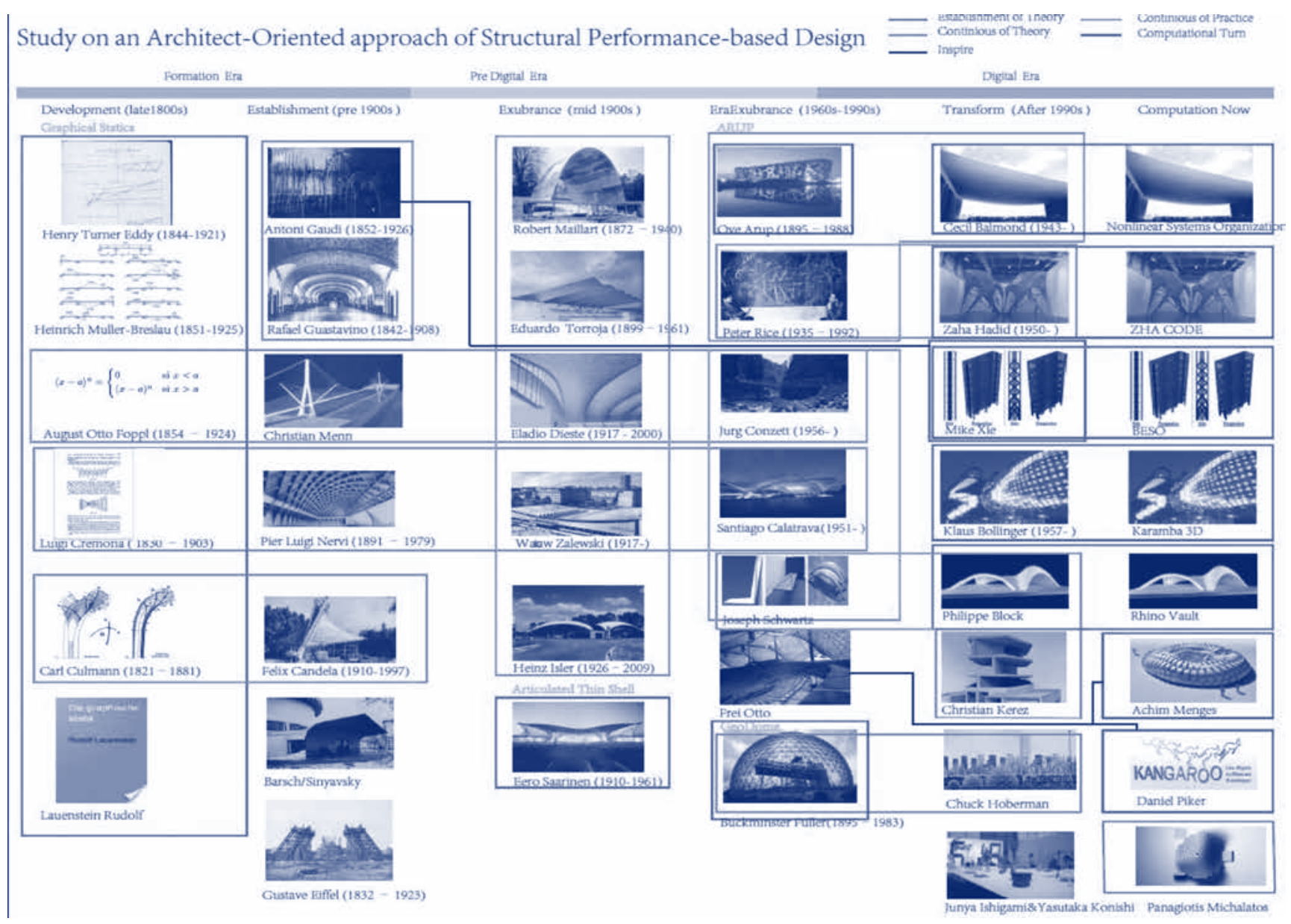

Over past few decades, in academia GSD, MIT, Columbia, Michigan and many other architecture schools established performance-related architecture design subjects. The progressive experimental Schools like AA, SCI-ARC and RPI to name a few, even developed their own performance-focused postgraduate programs: EMTECH, ESTM and CASE. In view of current developments in the technology of architectural design research and practice, the performative morphology has become a growingly important formation factor.

\section{Three Eras}

Among those methods, structural performance based method has been developing through out all eras of architecture history. The structure engineers consider the personal safety of technical operations, construction and construction-related physical properties, architecture must take into account the social function of the building, namely as a communication framework for ordering and guidance functions, operations and by its appearance readability.

The traditional structural Performance design process is an passive design method that focus on meeting the needs of structural laws and regulations. Architects are led by structural engineers who verify, evaluate and approve the design to make the building comply with the established performance requirements. But through the improvement of computational force and rapid prototyping technology over the past decade, the structural performances of architecture can be simulated, analyzed and optimized. This made it possible for architects to closely collaborate with engineers, push the boundary of architecture design and create an articulation between the spatial and structural quality of architecture. And a new structural performance based architectural design methodology emerged.

Graphic Statics theory began in the late 19th century, the development of graphical statics theory would force a two-dimensional visualization of the structure, making the architects and engineers to design and build under the aid of this tool, thus contributing to the structural performance of buildings affect the design began slowly formed. The development of mid-20th century, due to the needs of the entire community for large-span space gradually improve, architects began to deal with more complex structure, while the impact generated by the form of the period thought, there are some areas of the building through a three-dimensional physical model experiments on the structure performance in the form of literal exploration. This also marks the structural properties of architectural design graphic enlightenment came after experiencing mechanical construction of the era, pre-project types and understanding of the technology is also influential, Pedersen use the famous Forth Rail Bridge (The Forth Bridge ) designs a framework to explain and sell their Pedersen bicycle. After the 1990s, with the advent of the computer age, a new method of calculating the structure and analysis tools have emerged. More 
dynamic and interactive way of making structural analysis based on morphological properties of building multi-dimensional multi-objective to generate possible. Since then, the construction sector entered the digital age metaplasia shaped structure based on performance.

From an architect's perspective, the development process of Structure Performance based Architectural Design is a non-liner process consist with varies branch and multiple layers. Chronologically, it can be be divide to 3 eras (Formation era, Pre-Digital era and Digital Era) and 6 stages (The Development, The Establishment, The Exuberance, The Post-Exuberance, The Transform and The Computation Now. )

\section{Formation Era}

\subsection{The Development}

The Formation era start from late 18th century, the invention of steel construction and reinforced concrete technology made it possible for engineers to construct high-rise, big-foot print, curvature buildings. At the same time, architects try to explore the form finding possibilities provide by new construction method and material. The very early Structural Performance-based method Graphic statics, which was introduced during the same period, became an important tool for engineer and architect to communicate, collaborate and experiment with. Karl Cullmann coined this theory and his fellow students start to develop and practice this method. Müller Bresalu taught in Berlin, August Föppl taught in Munich. Henry Turner Eddy published his Analytical Geometry (1874) And Researches in Graphical Statics (1878) in english, these works became wide spreading in US. Later, Prof. Lauenstein summarized the findings some 100 years ago in his Die graphische Statik, his Course Books were eventually still part of some library. Jerome Sondericker wrote in 1904 his book $\bigotimes$ Graphic statics, with applications to trusses, beams and arches.

\subsection{The Establishment}

After the invention of this theory numerous architects tried to establish structural based architectural design method. For example: Rafael Guastavino Jr. push the Graphic Statics theory to a new stage that designed using equilibrium methods of analysis and his contributions to the graphical analysis of domes. He was among the first to adapt new innovations in the use of graphical methods for his design and construction projects. Gaudi had taken the principle of graphic statics one step further when he used it to determine the directions of the thrusts that emerged from the bases of the vaults. He then aligned the supporting columns along these lines of thrust, which allowed him to avoid constructing buttresses that he considered unnatural. Therefore, in the Sagrada Familia, Gaudi created a new architectural style that was original, simple and aesthetic. In the pre-formation era, this engineer's contribution to architecture, this structural performance-based method, served as verification instrument for architects to gain better understand of the structural condition and make a response to it. They all played an instrumental view in pre-digital era's structural performance architectural design. Although it enabled innovative architects by applying devices such as theory to create unbelievable complex spatial condition in a few centuries ago, it could not be prevented from was recognised as unimportant design tool.

\section{Pre-Digital era}

\subsection{The Exuberance}

Structure performance based architecture design enter its exuberance era during mid $20 \mathrm{~h}$ century. The thin shell structure played an increasingly important role since 1940s. At first, it is the state of art graphic statics structural knowledge made it possible for architect to produce reliable result and meet structural requirement of large civic works. Secondly, the thin shell structure follows clear structure principle and geometric principle, that is important for rapid production of large numbers of buildings. Finally, it is an economical solution, the use of material, the use of labor resource and construction time has been reduce to minimum. Because of the rapid development and rebuild after WWII, the thin shell construction start to be increasingly important. The idea of framing social Interaction with an open, light and transparent space also provided architects with opportunity to continue following a historical lineage of design research within the domain of physical form-finding such as the hanging chains, soap films et.al, pioneered by the likes of Eladio Dieste, Heinz Isler, Frei Otto, Felix Candela and others.

\subsection{The Post-Exuberance}

1959 establishment of the International Association of Light shell structure (IASS) has attracted academic attention to the housing structure, and implements such as grid structure, further development of the tensioned membrane structures, such as the structure and form. Architects and structural engineers continue to develop lightweight structural system of interest, such as the construction techniques for the analysis and spatial structure of the shell and other issues

However, there were discussions about this methods: Firstly, the design based on physical models which might have unique result that unrepeatable. This result to limited number iterations of experiment and may lead to undesirable outcome. Secondly, these design were produced in extremely precise way, which may reduce the creativity of design process. At last, these methods only provide finite number of results that made it difficult for architects to find potential optimum material, aesthetic and structural solution. These draw backs drive architects to search for new tools and technologies and improve the design method.

\section{Э. Digital era}

\subsection{The Transform}

Unlike homogenization modernist design methods, design methods based on the structural properties of the structural performance analysis using simulation techniques, a clearer understanding of the force distribution, and with the guidance material accurate and faithful expression in response to the force distribution, structure cross-section at the same time, and to optimize this design.

In Transform time, due to the topology optimization methods and improvement, architects began to try their form generation method used in the design of large buildings form on. Evolutionary structural optimization method (ESO) that is the current structure of the algorithm is widely used, the basic concept is very simple, which is based 
on the location of the material structure gradually from inefficient parts or materials reallocated to the most underutilized needed, with the greatest improve the performance and structure of the system reduces the maximum weight limits to. (2004) in Arata Isozaki and structural engineers to design Sasaki Mu Lang Qatar International Conference Centre, this approach as the dominant molding method also determines the basic shape and spatial relationships of the building. But from the point of view of construction levels, the building to some extent a departure from the original intention of evolutionary structural optimization method, since a single continuous homogeneous material evolutionary structural optimization method required in the construction process into a steel plate fitting skin, reinforced cement composite inner support grid structure, the structural performance advantages become blurred, difficult to evaluate. Structural Performance Practice architect at this stage tend to focus on intuitive feel, as a form-finding tool to help architects achieve complex forms, generate specific space, but due to imperfect production technology and facilities, the design is often difficult to truly reflect structural optimization in mind, it is difficult to obtain the optimal structure solutions.

\subsection{Computation Now}

In Digital era, it becomes crucially important and showing possibilities in addition to its analytic use and beyond its instrumentality. On one hand, the graphic static theory has been translated into digital algorithms, thus architects could have more clear understanding of this traditional structure analysis it could help architects to optimize structure and achieve better structural performance with a lower budget. And architects also developed it into form finding tools to create highly performative, adaptive and dynamic structure systems. Furthermore it also provides solutions for emerging algorithmic design such as agent-based design practices to find potential sophisticate and adaptive structural solution for their hypercomplex geometry. The FEM made it possible for the architect and engineers like Mark Burry and engineer like Mike Xie to decode Gaudi's mysterious geometric design and realize the construction work of Sangrada Familia. The topological optimization method also inspired architects like Mike Xie, Panagiotis Michalatos and produce softwares like BESO and Millipede plug-in for architects to grasp the idea of topological optimization at beginning of design process.

\section{Reflection and Conclusion}

At first, the Structural Performance based design method develops and employs computational techniques and digital fabrication technologies to unfold innate structural characteristics and specific latent performative capacities. Extending the concept of structural systems by embedding their material characteristics, geometric behaviour, manufacturing constraints and assembly logics within a computational model, the systems manipulations can be evaluated in relation to structural performance. It also provides possibilities of rethinking the prevailing notion of efficiency through the effectiveness of structural systems.

Secondly, Structural Performance based design is neither simply using form-active structure primitives as driver of design, nor using structural behavior properties as a traditional form-finding tool. It establishes a new form of collaboration between architects and engineers and it made it possible for architects to develop a new multi-objective form-finding process which across multiple hierarchies that define complex architectural systems. The structural performance optimization process makes the design more responsive and adaptable. Performance-based novel synergy effects emerge from highly differentiated morphologies developed with this method.

Finally, the structural performance based methods is the method that enable architects to involve and play a more important and engaging role in the rationalization and realization of complex geometrical structural design, yet it also help architects to improve the performance of projects. More importantly, architects could use it as vehicle to create new form to articulate architectural space and structural members.

Therefore we can say, this method appears to be a prerequisite for building design methods and techniques for form finding. It is intended to outline new possibilities in creating new forms, and it is able to articulate space, material, social need and information of architecture with higher level of performance than previously possible.

\section{References}

[1]Patrik Schumacher, The Autopoiesis of Architecture, A New Framework for Architecture [M], section, 2.5 The Necessity of Demarcation, John Wiley \& Sons Ltd., London 2010

[2]Patrik Schumacher, Studio Kick Off Lecture [R], University of Applied Arts Vienna, 2014

[3] https://blogs.ethz.ch/digital-collections/page/28/

[4] Graphic Statics with Applications to Trusses, Beams and Arches [M].p5-p20, Jerome Sondericker. J.Wiley\& sons, 1903.

[5]AmrAly Hassan Fangary Graphic statics analysis of gothic vaults[M] p65-p69 2010

[6]Anna Fernandez TorrellesHistory of architecture: AntoniGaudí [M], p26-p34

[7]Brumfield, William Craft. The Origins of Modernism in RussianArchitecture [M]. Berkeley: University of California Press, p20-p29, c1991 1991.

[8]https://www.iass-structures.org/index.cfm/membr.join

[9]Toni Kotnik And Joseph Schwartz, The Architecture Of Heinz Isler [J], Journal Of The International Association For Shell And Spatial Structures, Vol.52, Nr.3, 185-190, 2011

[10]WacławZalewski: Shaping Structures [M], Wolk Gallery, MIT School of Architecture and Planning, 2006

[11]Patrik Schumacher, Studio Kick Off Lecture [R], University of Applied Arts Vienna, 2013

[12]Asmaljee, Zaahir, Form-finding of thin shell structures [M], p58-p61, University of the Witwatersrand, f Master of Science in Engineering.

[13]Asmaljee, Zaahir, Form-finding of thin shell structures [M], p58-p61, University of the Witwatersrand, f Master of Science in Engineering.

[14]Equilibrium systems Studies in Masonry Structure by Philippe Block [M] Massachusetts Institute of Technology June 2005 